\title{
Lay Consultations in Heart Failure Symptom Evaluation
}

\author{
Katherine M. Reeder ${ }^{1 *}$, Jessica L. Sims ${ }^{2}$, Patrick M. Ercole ${ }^{3}$, Shivan S. Shetty ${ }^{4}$, \\ Michael Wallendorf ${ }^{5}$ \\ ${ }^{1}$ Unity Point Health - Des Moines Faculty, Mercy Medical Center North Iowa Faculty E-mail: kcmvrk@yahoo.com \\ ${ }^{2}$ University City Children's Center 6646 Vernon Ave. St. Louis E-mail: jlynnrasmussen@gmail.com \\ ${ }^{3}$ Director of Analytics, Sansom Consulting, Glendale, AZ E-mail: patrick@sansom.com \\ ${ }^{4}$ Medical Student, 2017-21 Kansas City University of Medicine \& Biosciences 1750 Independence Avenue Kansas City \\ E-mail: shivan.s.shetty@gmail.com \\ ${ }^{5}$ Washington University School of Medicine, Division of Biostatistics 660 South Euclid Ave. St. Louis \\ E-mail: mwallendorf@wustl.edu
}

Received: July 13, 2017; Accepted: August 3, 2017; Published: September 27, 2017

*Corresponding author : Katherine M. Reeder, PhD, RN, FAHA, Unity Point Health - Des Moines Faculty, Mercy Medical Center North Iowa Faculty, 250 S. Crescent Drive, Mason City, IA 50401 641-494-5300.E-mail: kcmvrk@yahoo.com

\section{Abstract}

Purpose: Lay consultations can facilitate or impede healthcare. However, little is known about how lay consultations for symptom evaluation affect treatment decision-making. The purpose of this study was to explore the role of lay consultations in symptom evaluation prior to hospitalization among patients with heart failure.
\end{abstract}

Methods: Semi-structured interviews were conducted with 60 patients hospitalized for acute decompensated heart failure. Chisquare and Fisher's exact tests, along with logistic regression were used to characterize lay consultations in this sample.

Results: A large proportion of patients engaged in lay consultations for symptom evaluation and decision-making before hospitalization. Lay consultants provided attributions and advice and helped make the decision to seek medical care. Men consulted more often with their spouse than women, while women more often consulted with adult children.

Conclusions: Findings have implications for optimizing heart failure self-management interventions, improving outcomes, and reducing hospital readmissions.

Key words: Heart Failure, Self Care, Lay Consultations

\section{Introduction}

Heart Failure (HF) is a chronic and often debilitating condition, affecting over 5 million Americans. Chronic HF is associated with frequent, acute exacerbations and recurrent hospitalizations $[1,2]$. Although several positive studies have reported significant reductions in HF-related hospital readmissions health care resource utilization for patients with HF is among the highest of any medical condition, especially among Medicare beneficiaries [3-7,8]. Older adults hospitalized for HF are at great risk for rehospitalization, with 30-day readmission rates as high as $25 \%[9,10]$. Many rehospitalizations could be prevented with improved HF self- management [11,12]. Despite recent attention to HF transitional care and self-management programs focused on reducing hospital readmissions and avoiding financial penalties, research on the post-discharge environment, where HF self-management occurs, is virtually absent from the healthrelated literature [1,13].

A significant aspect of the post-discharge environment is the patient's social network, which is widely recognized as playing an important role in health outcomes $[13,14]$. Persons in a patient's social network can provide various types of support (emotional, informational, appraisal, and instrumental) that serve different purposes $[15,16]$. In the health-related literature, lay consultations often describe interactions that patients have with people in their social network [17]. Lay consultations often 
occur before contact with healthcare professionals, yet little research exists about how people make treatment decisions and the nature and source of lay consultations. Current research specific to lay consultations in HF is limited; thus, we begin by reviewing literature on lay consultations among patients with other cardiovascular conditions.

In research on lay consultation among patients with cardiovascular diseases, including Acute Myocardial Infarction (AMI), patients solicited opinions and advice from persons in their social network to assist them in symptom evaluation and decisionmaking [18-20]. As a component of a study on pre-hospital delay (i.e., the time between symptom onset and hospital arrival), data on lay consultations were collected not only from patients, but also directly from the lay consultants with whom patients interacted about their symptoms prior to seeking professional care [19]. No differences in pre-hospital delay were found between patients who engaged in lay consultations prior to hospitalization compared to those who did not. Virtually no agreement between patient and lay consultant symptom attributions was observed. The advice that lay consultants said they gave to patients (i.e., seek medical care or other) had no discernible impact on prehospital delay. However, patients who recalled being given advice to seek medical care by lay consultants delayed seeking treatment significantly longer than those who did not recall having received advice to seek treatment, suggesting a Rashoman effect [21]. Other studies from the cardiovascular literature also found that symptomatic patients who talked with lay consultants about their symptoms took longer to determine whether their symptoms required professional care, especially among women [18,22-26]. These findings illustrate the complexities of social influence processes, including lay consultations on symptom evaluation and treatment-seeking decision-making.

Other cardiovascular literature illustrates the differing roles that lay consultants play for patients, as well as the possible influences of age and gender in lay consultations and healthcareseeking behaviors. For example, Schoenberg, et al. found that older adults (vs. middle-aged adults) with cardiovascular disease were significantly more likely to rely on others (most frequently spouses or adult children) for making the decision to seek professional care [20]. In a study of patients hospitalized with AMI, Martin et al. found that most of their sample engaged in lay consultations prior to hospitalization, and that women talked to significantly more lay consultants than men [25]. However, women were significantly less likely than men to receive cardiac attributions for their symptoms or to receive advice to seek professional care, suggesting the potential for the gender bias that heart disease predominantly affects men (vs. women).

Research that examines the role of lay consultations in symptom evaluation and healthcare-seeking for patients with $\mathrm{HF}$ will build upon existing evidence on symptom self- management and treatment decision-making interventions aimed at effectively improving outcomes. Because the manner in which lay consultations influence symptom evaluation and healthcare- seeking behavior is largely unknown, this study is an important initial step in developing evidence on the role of lay consultations in symptom evaluation among patients hospitalized with acute decompensated HF. The purpose of this study was to describe the nature and source of lay consultations among patients hospitalized with HF, using an integrative theoretical approach on HF self-care and common sense models in health and illness [27,28-30].

\section{Methods \\ Design and Sample}

Semi-structured interviews were conducted with 60 patients admitted to the hospital for acute decompensated HF to explore patient perceptions of experiences with lay consultations for symptom evaluation leading up to hospitalization. This project was part of a broader study examining the timeliness of symptom recognition, interpretation, and reporting in patients hospitalized with HF [31]. Approval for this study was obtained from the university institutional review board.

\section{Data Collection}

Baseline Data. Trained research nurses collected baseline demographic and clinical data from patients' self-reports and medical records.

Interview Procedure and Variables. Interviews were conducted by trained research nurses. Interviews focused on patients' perceptions of consultative conversations they had with laypersons during the symptomatic period leading up to hospitalization. Specifically, whether patients engaged in lay consultations about symptoms prior to hospitalization was verified; and if so, patients' perceptions of lay consultants' symptom interpretation and advice about what to do for symptoms was explored.

Patients were asked if they had spoken to or consulted with anyone in their social network before contacting a health care provider or seeking professional care for their symptoms (yes or no). If yes, patients described the nature of their consultations with the person they interacted with most about symptoms. Next, patients who engaged in consultations with other laypersons were asked whether anyone they talked to about their symptoms told them what they thought was causing their symptoms (yes or no). If yes, patients were asked to describe what lay consultants said was causing symptoms. Patients were also asked whether lay consultants gave them advice on what to do about symptoms (yes or no); and if yes, patients described the advice lay consultants gave them. Lay consultants' advice was coded as seek professional care or try a self-care strategy. Inter-rateragreement of coded open-ended interview item responses by two independent trained research nurses was observed.

\section{Data Analysis}

Demographic and questionnaire data were analyzed using the 
International Business Machines (IBM) Statistical Package for the Social Sciences (SPSS), Windows version 21.0 software (Armonk, New York, United States) and SAS 9.3 (Cary, North Carolina, United States). Demographic summary statistics were computed. Chi-square tests, Fisher's exact tests, and multivariable logistic regression were used to examine associations. Alpha was set at .05

\section{Results}

\section{Sample Demographics}

The mean age of this sample was $63 \pm 14$ years, with a range from 25 to 88 years. Nearly half of the patients were women, Black, and married (Table 1). For 24 (40\%) patients, the study

\section{Table 1}

\section{Demographic Summary $(N=60)$.}

\begin{tabular}{lrr} 
Variable & $\mathrm{n}$ & $\%$ \\
\hline Gender & & \\
$\quad$ Male & 33 & 55.0 \\
$\quad$ Female & 27 & 45.0 \\
Age & & \\
$\quad 18-64$ & 32 & 53.3 \\
$\quad 65-89$ & 28 & 46.7 \\
Ethnicity & & \\
$\quad$ White & 33 & 55.0 \\
$\quad$ Black & 25 & 41.7 \\
$\quad$ Multi-racial & 2 & 3.3 \\
Marital Status & & \\
$\quad$ Married & 29 & 48.3 \\
$\quad$ Not married & 31 & 51.7 \\
Children under 18 years old & & \\
$\quad$ Yes & 12 & 20.0 \\
$\quad$ No & 47 & 78.3 \\
Employment status & & \\
$\quad$ Yes & 8 & 13.3 \\
$\quad$ No & 48 & 80.0 \\
\hline
\end{tabular}

hospitalization was the first time they had been hospitalized for acute decompensated HF.

\section{Lay Consultations}

Before hospitalization, a large majority of patients ( $\mathrm{n}=$ 47, 78.3\%) engaged in consultations about symptoms with laypersons from their social network. Most often, they discussed symptoms with their spouse $(55.3 \%)$ or adult children $(23.4 \%)$. In this study, spouse was defined as any domestic life partner. Of the 47 patients who interacted with others about their symptoms, $43(91.5 \%)$ said they talked face-to-face or by telephone with their lay consultants, as symptoms actively occurred.

In examining gender differences, we found that significantly more men engaged in lay consultations than women (Table 2), $(\mathrm{p}=.001)$. Among patients who engaged in lay consultations, men (vs. women) more often discussed symptoms with their spouse $(\mathrm{p}=.017)$. Women (vs. men) more frequently discussed symptoms with their adult children $(\mathrm{p}=.004)$. To account for there being significantly more married men $(n=21,63.6 \%)$ than married women $(n=8,29.6 \%)$ in our sample $(p=.009)$, logistic regression was used to examine associations of gender and marital status. In the logistic regression analysis, both being married $(\mathrm{p}=.025, \mathrm{OR}=12.05)$ and male gender $(\mathrm{p}=0.025, \mathrm{OR}=$ 7.09) were associated with increased likelihood of engaging in lay consultations. For engaging a spouse as lay consultant, marriage alone was positively associated ( $\mathrm{p}=0.0001, \mathrm{OR}=222.5)$; and male gender was not significantly associated $(p=0.075,0 R=9.5)$.

\section{Lay consultant symptom attributions and advice.}

Twenty-four (51.1\%) patients reported that the person they talked to most about symptoms told them what they thought was causing their symptoms. Of those who received attributions, most often lay consultants attributed patients' symptoms to their heart ( $\mathrm{n}=17,70.8 \%)$, lungs $(\mathrm{n}=9,37.5 \%)$, or diabetes ( $\mathrm{n}$ $=8,33.3 \%$ ). Less frequently, patients said their lay consultants attributed symptoms to other causes such as diet, stress, fluid intake, and weight gain, as well as the common cold or stomach virus. Despite only 24 patients receiving symptom attributions from consultants, $41(87.2 \%)$ patients said they received advice from their lay consultant about what to do for their symptoms. Most often, patients received advice to seek medical care ( $\mathrm{n}=$ $39,95.1 \%)$. Among patients who received advice from their lay consultant, most (73.2\%) said they took the advice given and acted on the advice within 2 days.

\section{Decision-making.}

When asked who most influenced their decision to seek professional care for symptoms, 48 (80\%) patients indicated their decision was self-directed. Twenty (33.3\%) patients said their spouse, and 9 (15\%) patients said their adult children influenced their decision to seek care. Men significantly more frequently said their spouse was instrumental in making the decision to seek care, compared to women $(\mathrm{p}=.001)$. Though when examining only patients who were married, gender was not 
Table 2

Patient Reports of Lay Consultation by Gender ( $N=33$ men; $N=27$ women).

\begin{tabular}{lrrr} 
Variable & $\begin{array}{r}\text { Men } \\
\mathrm{n}(\%)\end{array}$ & $\begin{array}{r}\text { Women } \\
\mathrm{n}(\%)\end{array}$ & P-Value \\
\hline $\begin{array}{l}\text { Engaged in lay consultations for symptom } \\
\text { evaluation }\end{array}$ & $31(93.9)$ & $16(59.3)$ & 0.001 \\
$\begin{array}{l}\text { Spouse made decision to seek care } \\
\text { Among patients with lay consultants }\end{array}$ & $17(51.5)$ & $3(11.1)$ & 0.001 \\
$\quad$ Lay consultant was spouse & $21(67.7)$ & $5(31.3)$ & 0.017 \\
$\quad$ Lay consultant was adult child & $3(9.7)$ & $8(50.0)$ & $0.004 \dagger$ \\
$\begin{array}{l}\text { Among patients who were married } \\
\quad \text { Spouse made decision to seek care }\end{array}$ & $16(76.2)$ & $3(37.5)$ & $0.08 \dagger$ \\
$\quad$ Lay consultant was spouse & $20(95.2)$ & $5(71.4)$ & $0.15 \dagger$ \\
\hline
\end{tabular}

† Fisher's Exact Test

a significant predictor of having a spouse influence the decision to seek professional care $(\mathrm{p}=.08)$.

\section{Discussion}

Across much of the health-related literature, social support and lay consultation are concepts typically used to describe health-related interactions with members of one's social network. Yet, both of these are broad terms that can encompass many different actions such as advice-giving, decision-making, or just listening. Specific aspects of lay consultations that contribute to health outcomes are not well understood. This systematic assessment on lay consultations in HF contributes to the literature by highlighting the role of lay consultations in HF symptom evaluation and healthcare-seeking decision-making in the post-discharge environment.

Living with HF requires ongoing, life-long symptom management, including symptom monitoring and evaluation, as well as accurate and timely treatment decision-making. Chronic HF self-management may not be undertaken alone, as members of patients' social network may be called upon to listen to descriptions of symptoms, help evaluate symptoms, and offer treatment advice for symptom relief. In this study, we found that the majority of patients reported discussing their symptoms with a lay consultant, most often their spouse or adult children prior to hospitalization. Patients also reported receiving symptom attributions and advice from their lay consultants. Lay consultant attributions and advice most often specified a cardiac problem and the need to seek medical attention, respectively. Interestingly, 41 patients received advice, while only 24 patients received symptom attributions. Thus, some lay consultants may have provided advice to seek care for symptoms, knowing something was wrong with the patient, but without being able to name what they thought was the cause of patients' symptoms. The majority of patients said that they took the advice of their lay consultant and acted on the advice within two days. In this study, lay consultants assisted patients with important aspects of self- management, symptom evaluation, and treatment decision-making.

This study also identified specific variables that characterized the nature of lay consultations. Specifically, differences between men and women in lay consultations were found. First, men engaged in lay consultations more frequently than women. Second, men consulted with their spouse more frequently, while women more often consulted with their adult children. However, marital status accounted for some of the difference in who participants engaged as lay consultants and who influenced the decision to seek medical care.

Though results of the logistic regression analyses implicate marital status in the nature of lay consultations, we contend that gender differences may underlie this finding. For example, heart disease typically affects women (vs. men) later in life and older women ( $\geq 65$ years of age) are less likely to be married than older men [8,32]. Based on these national statistics, women with HF may be less likely to be married (as in our sample) and have access to a lay consultant who lives in their home. The laypersons patients consult with may be due, in part, to differences in the composition and geographic proximity of social networks, as well as the availability of laypersons for consultation upon request. Spouses may be more likely to actively participate in patients' 
medical care by attending healthcare appointments and receiving educational information, which may expedite patients' response to symptoms and implementation of self- care strategies or seeking professional care. In addition, spouses may be more likely than lay consultants who do not live with patients to undergo the same lifestyle and dietary changes that patients undergo, as they support their loved one living with HF. Thus, understanding a patient's social network and their access to lay consultants has implications for current practice and HF self-care interventions.

Recognizing the research clearly indicates that most people engage in lay consultations can alert practitioners to the need to help patients identify lay consultants that are willing to engage in educational programs and interventions with patients. Understanding the makeup of patients' social networks and who they engage or don't engage as lay consultants for symptom evaluation allows practitioners to target persons most influential in patient self-management.

Additional research is needed to better pinpoint areas for targeted instruction and to identify the impact of lay consultation on outcomes, including rehospitalization. Future directions for research include how lay consultations impact self-management behaviors, including self-care treatments and the timeliness in which professional care is sought. In this study, participants most often engaged in lay consultations as symptoms actively occurred, but we do not know (a) the impact of the timing of lay consultations relative to the variability in illness symptoms that occur throughout the symptomatic period and (b) how communication style and technologies (face-to-face, telephone, or e-mail) influence lay consultations and subsequent healthcareseeking behavior.

In addition to examining patients' perspectives of lay consultations, research is needed that includes detailed descriptions of the exchanges that take place between patients and lay consultants from the perspective of the lay consultants. Then, it will be important to identify whether engaging in lay consultations about symptoms impacts outcomes, as AMI investigations found that engaging in lay consultations, especially with close family members, significantly prolonged the time patients took to seek professional care for their symptoms $[18,33,34]$. In this line of research on HF self-care in the postdischarge environment, it is important to design studies that will improve agreement between patients and their lay consultants on symptom perceptions in order to expedite symptom reporting and early treatment-seeking.

More broadly, patients' social networks may have a positive impact on health behaviors, including making lifestyle changes and implementing self-care strategies that are not only important HF secondary prevention behaviors, but also provide primary prevention for other co- morbidities commonly associated with HF. Studies have shown promising effects of social networks in promoting lifestyle changes and supporting healthy behaviors $[16,35,36]$. As demonstrated in this study, patients with HF engaged in lay consultations for symptom evaluation before hospitalization. Future investigations need to specifically identify the ways in which lay consultants can promote effective self-care to support patients in symptom interpretation and treatmentseeking decision-making, improve HF outcomes, and avoid hospitalization.

The post-discharge environment, where most of the selfmanagement of chronic illness occurs, has gained renewed attention in light of recent changes in reimbursement to hospitals for 30-day readmissions [13,14]. Though further research is needed to better understand the role of lay consultations in HF self-management, findings from this study indicate the need for interventions that include important aspects of self-management unique to the post-discharge environment, where the majority of HF self-care resides. Patients self-manage their HF outside the realm of formal healthcare systems; thus, patients' social network can be an important initial source of support and influence on self-care decision-making. The lay consultants with whom patients discuss health concerns most need to be encouraged to accompany patients to out-patient clinic appointments and to be present when hospital discharge instructions are given. In addition, lay consultant roles may be expanded beyond symptom evaluation to include supporting patients in sustaining high levels of self-care maintenance by adhering to prescribed HF selfcare regimens.

\section{Limitations}

Data on lay consultations were collected during patient interviews after patients were hospitalized, and thus results are limited to patients' recall and reporting of retrospective symptom scenarios. To address this limitation, interview questionnaires were developed using theoretically tested interview methods to enhance recall of daily routine events [37]. Though patient responses are subjective in nature, patients' perceptions are important in understanding how patients approach symptom self-management in the post-discharge environment, particularly the use of lay consultations in symptom evaluation. Only by understanding how patients self-manage their HF beyond the purview of a hospital stay or clinic visit will we be able to more fully address underlying problems associated with recurrent hospitalizations in persons living with chronic HF.

The sample in this study included patients from a limited geographical area, with strict inclusion and exclusion criteria, limiting the generalizability of the results. Future studies are needed that include a larger and broader range of patients who self-manage their HF in order to replicate findings of this study and use findings in intervention and implementation research.

\section{Conclusion}

The purpose of this study was to explore the role of lay consultations for symptom evaluation and decision-making leading up to a hospitalization for acute decompensated HF. Lay consultations can impact evaluative processes in self- 
management, as patients discuss their symptoms with and receive attributions and advice about symptoms from their lay consultants. This study adds to the HF literature by establishing the use of lay consultations for symptom evaluation and decisionmaking prior to hospitalization for HF and identifying possible patient characteristics that may impact the use of lay consultation. These findings have implications for how interactions within patients' social networks can optimize HF self-management, improve outcomes, and reduce hospital readmissions.

\section{Acknowledgement}

Research reported in this publication was supported by the National Institute of Nursing Research of the National Institutes of Health under award number R00NR012217. The content is solely the responsibility of the authors and does not necessarily represent the official views of the National Institutes of Health, National Institute of Nursing Research.

Authors have reported no conflict of interests.

\section{References}

1. Gheorghiade M, Vaduganathan M, Fonarow GC, Bonow RO. Rehospitalization for heart failure: problems and perspectives. J Am Coll Cardiol. 2013;61(4):391-403. doi: 10.1016/j. jacc.2012.09.038

2. Yancy CW, Jessup M, Bozkurt B, Butler J, Donald E C Jr, Drazner MH, et al. 2013 ACCF/AHA guideline for the management of heart failure: a report of the American College of Cardiology Foundation/American Heart Association Task Force on Practice Guidelines. Journal of the American College of Cardiology. 2013;62(16):e147-239. doi: 10.1016/j.jacc.2013.05.020

3. Austin LS, Landis CO, Hanger KH Jr. Extending the continuum of care in congestive heart failure: an interactive technology self-management solution. J Nurs Adm. 2012;42(9):442-426. doi: $10.1097 /$ NNA.0b013e3182668342

4. Powell LH, Calvin JE Jr, Richardson D, Janssen I, Mendes de Leon CF, Flynn KJ, et al. Self-management counseling in patients with heart failure: the heart failure adherence and retention randomized behavioral trial. JAMA. 2010;304(12):1331-1338. doi: 10.1001/jama.2010.1362

5. Smeulders ES, van Haastregt JC, Ambergen T, Uszko-Lencer NH, Janssen-Boyne JJ, Gorgels AP, et al. Nurse-led self-management group programme for patients with congestive heart failure: randomized controlled trial. J Adv Nurs. 2010;66(7):14871499. doi: 10.1111/j.1365-2648.2010.05318.x

6. Sochalski J, Jaarsma T, Krumholz HM, Laramee A, McMurray JJ, Naylor MD, et al. What works in chronic care management: the case of heart failure. Health Aff (Millwood). 2009;28(1):179189. doi: $10.1377 /$ hlthaff.28.1.179

7. Wakefield BJ, Boren SA, Groves PS, Conn VS. Heart failure care management programs: a review of study interventions and meta-analysis of outcomes. J Cardiovasc Nurs. 2013;28(1):819. doi: 10.1097/JCN.0b013e318239f9e1
8. Benjamin EJ, Blaha MJ, Chiuve SE, Cushman M, Das SR, Deo R; et al. Heart Disease and Stroke Statistics-2017 Update: A Report From the American Heart Association. Circulation. 2017;135(10):e146-e603. doi: 10.1161/ CIR.0000000000000485

9. Jencks SF, Williams MV, Coleman EA. Rehospitalizations among patients in the Medicare fee-for-service program. N Engl J Med. 2009;360(14):1418-1428. doi: 10.1056/NEJMsa0803563

10. Krumholz HM, Merrill AR, Schone EM, Schreiner GC, Chen J, Bradley EH, et al. Patterns of hospital performance in acute myocardial infarction and heart failure 30-day mortality and readmission. Circ Cardiovasc Qual Outcomes. 2009;2(5):407413. doi: 10.1161/CIRCOUTCOMES.109.883256

11. Fonarow GC, Abraham WT, Albert NM, Stough WG, Gheorghiade M, Greenberg BH, et al. Factors identified as precipitating hospital admissions for heart failure and clinical outcomes: findings from OPTIMIZE-HF. Arch Intern Med. 2008;168(8):847-854. doi: 10.1001/archinte.168.8.847

12. Schiff GD, Fung S, Speroff T, McNutt RA. Decompensated heart failure: symptoms, patterns of onset, and contributing factors. Am J Med. 2003;114(8):625-630.

13. Hersh AM, Masoudi FA, Allen LA. Postdischarge environment following heart failure hospitalization: expanding the view of hospital readmission. J Am Heart Assoc. 2013;2(2):e000116. doi: 10.1161/JAHA.113.000116

14. Collins SP, Storrow AB. Moving toward comprehensive acute heart failure risk assessment in the emergency department: the importance of self-care and shared decision making. JACC Heart Fail. 2013;1(4):273-280. doi: 10.1016/j. jchf.2013.05.002

15. Berkman LF, Glass T, Brissette I, Seeman TE. From social integration to health: Durkheim in the new millennium. Soc Sci Med. 2000;51(6):843-857.

16. Boutin-Foster C. Getting to the heart of social support: a qualitative analysis of the types of instrumental support that are most helpful in motivating cardiac risk factor modification. Heart Lung. 2005 Jan-Feb;34(1):22-29. doi: 10.1016/j. hrtlng.2004.09.002

17. Edwardson SR, Dean KJ, Brauer DJ. Symptom consultation in lay networks in an elderly population. J Aging Health. 1995 Aug;7(3):402-416.

18. Alonzo AA. The impact of the family and lay others on careseeking during life-threatening episodes of suspected coronary artery disease. Soc Sci Med. 1986;22(12):1297-1311.

19. Piamjariyakul U, Reeder KM, Wongpiriyayothar A, Smith CE. Coaching: An innovative teaching strategy in heart failure home management. In J. P. Henderson \& A. D. Lawrence (Eds.), NOVA Science: Teaching strategies (pp. 185-202). New York: NY: NOVA Science Publishers. 2011. 
20. Schoenberg NE, Amey CH, Stoller EP, Muldoon SB. Lay referral patterns involved in cardiac treatment decision making among middle-aged and older adults. Gerontologist. 2003;43(4):493502 .

21. Akutagawa R. Rashomon and Other Stories. New York: Liveright. 1952.

22. Bouma J, Broer J, Bleeker J, van Sonderen E, Meyboom-de Jong B, DeJongste MJ. Longer pre-hospital delay in acute myocardial infarction in women because of longer doctor decision time. J Epidemiol Community Health. 1999;53(8):459-464.

23. Dracup K, Alonzo AA, Atkins JM, Bennett NM, Braslow A, Clark LT, et al. The physician's role in minimizing prehospital delay in patients at high risk for acute myocardial infarction: recommendations from the National Heart Attack Alert Program. Working Group on Educational Strategies to Prevent Prehospital Delay in Patients at High Risk for Acute Myocardial Infarction. Ann Intern Med. 1997;126(8):645-651.

24. Gao Y, Zhang HJ. The effect of symptoms on prehospital delay time in patients with acute myocardial infarction. J Int Med Res. 2013;41(5):1724-1731. doi: 10.1177/0300060513488511.

25. Martin R1, Lemos C, Rothrock N, Bellman SB, Russell D, TrippReimer T, et al. Gender disparities in common sense models of illness among myocardial infarction victims. Health Psychol. 2004;23(4):345-353. doi: 10.1037/0278-6133.23.4.345.

26. Roger H. Sweet and Andrew C. Twaddle. An Exploration of Delay in Hospitalization.Inquiry.1969;6(2):35-41.

27. Riegel B, Dickson VV. A situation-specific theory of heart failure self-care. J Cardiovasc Nurs. 2008;23(3):190-196. doi: 10.1097/01.JCN.0000305091.35259.85.

28. Leventhal $H$, Benyamini $Y$, Brownlee $S$, Diefenbach $M$, Leventhal E A, Patrick- Miller L, et al. Illness representations: Theoretical foundations. In K. J. Petrie \& J. A. Weinman (Eds.), Perceptions of health and illness. Amsterdam: Harwood Academic.1997;19-45.
29. Howard Leventhal, Michael Diefenbach. The Active Side of Illness Cognition. In J. A. Skelton \& R. T. Croyle (Eds.), Mental representations in health and illness. New York: SpringerVerlag. 1991:247-272.

30. Leventhal H, Meyer D, Nerenz D. The common sense representation of illness danger. In S. Rachman (Ed.), Medical psychology. New York: Pergamon Press. 1980;2:17-30.

31. Reeder KM, Ercole PM, Peek GM, Smith CE. Pre- hospitalization symptom experiences in patients with heart failure. The Journal of Cardiovascular Nursing. 2013. doi: 10.1097/ JCN.0000000000000117

32. Administration on Aging. A profile of older Americans: 2012. 2012.

33. Dracup K, Moser DK. Treatment-seeking behavior among those with signs and symptoms of acute myocardial infarction. Heart Lung. 1991;20(5 Pt 2):570-575.

34. Turi ZG, Stone PH, Muller JE, Rude RE, Raabe DE, et al. Implications for acute intervention related to time of hospital arrival in acute myocardial infarction. American Journal of Cardiology. 1986;58(3):203-209. doi: 10.1016/00029149(86)90047-0

35. Hurdle DE. Social support: a critical factor in women's health and health promotion Health Soc Work. 2001;26(2):72-79.

36. Riegel B, Dickson VV, Kuhn L, Page K, Worrall-Carter L. Gender-specific barriers and facilitators to heart failure selfcare: a mixed methods study. Int J Nurs Stud. 2010;47(7):888895. doi: 10.1016/j.ijnurstu.2009.12.011

37. Kahneman D, Krueger AB, Schkade DA, Schwarz N, Stone AA . A survey method for characterizing daily life experience: the day reconstruction method. Science. 2004;306(5702):17761780. doi: 10.1126/science. 1103572 